
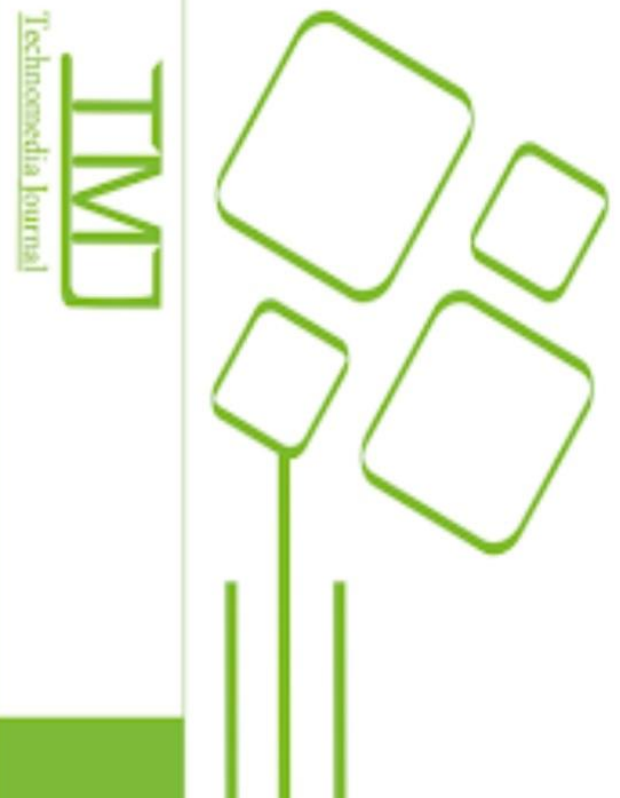

E-ISSN: 2528 - 6544

P-ISSN: 2620 - 3383

Vol.1 No.2 Februari 2017

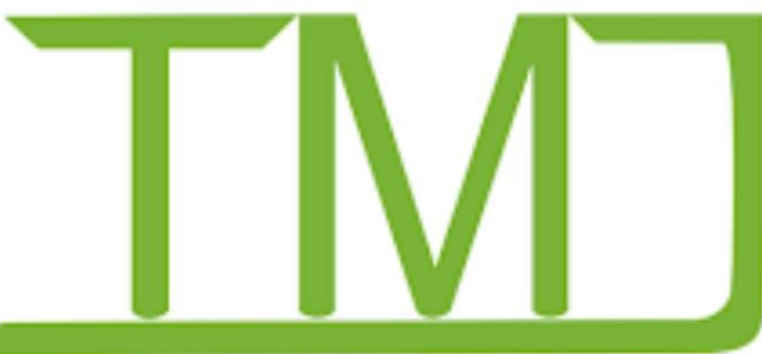

Technomedia Journal

iLearning Journal Center (iJC)

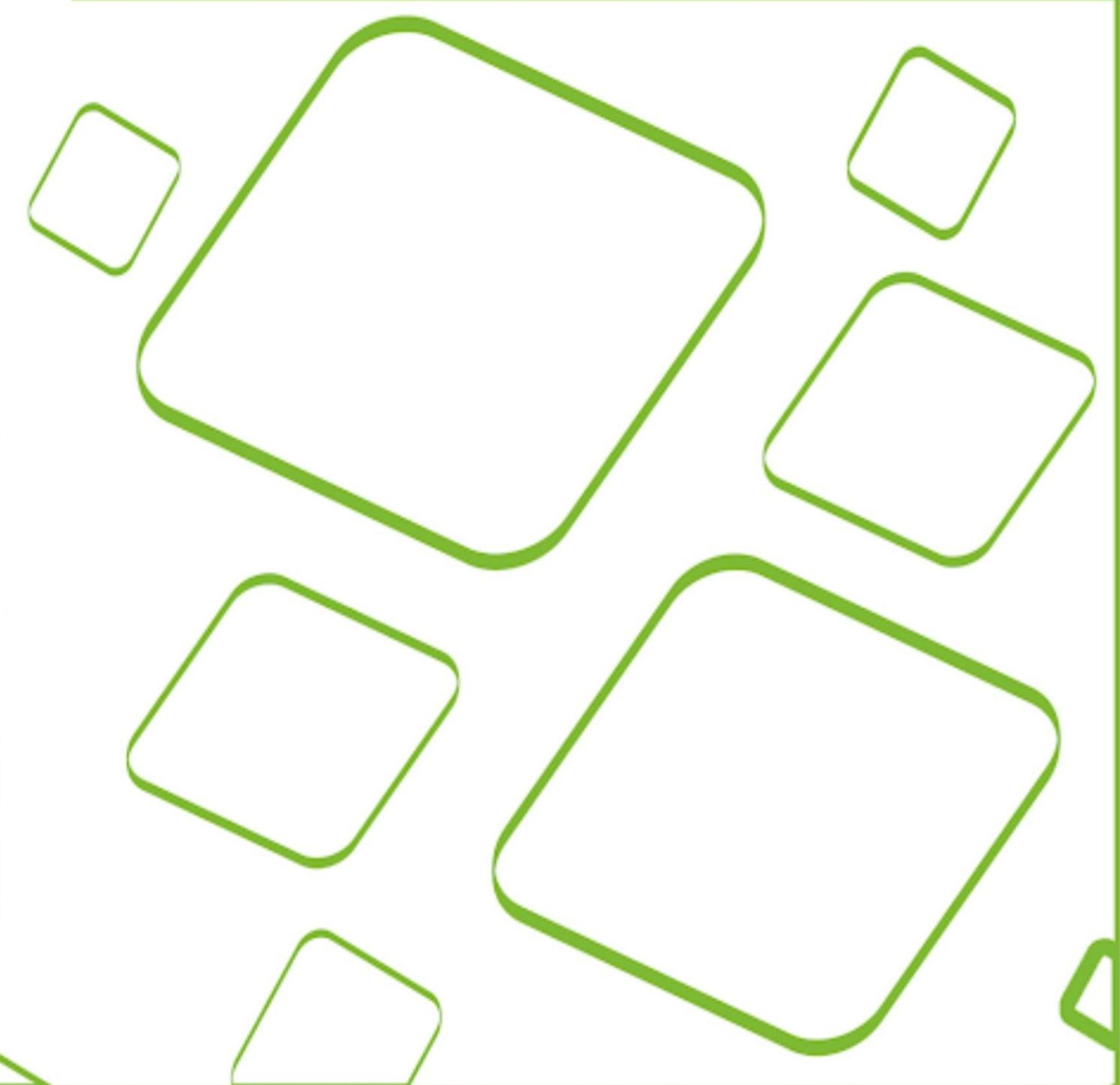


Technomedia Journal adalah jurnal elektronik ilmiah yang diterbitkan oleh Biro Publikasi Technomedia. Technomedia Journal terbit tiga kali dalam satu tahun Februari, Juni, dan Oktober yang berisi artikel hasil penelitian dalam bidang Sistem Informasi dan Teknologi Informatika.

\section{Ketua Redaksi :}

Ir. Untung Rahardja.,M.T.I

\section{Sekretaris Redaksi :}

Indri Handayani, S.Kom., M.T.I

\section{Mitra Bestari :}

Prof. Ir. Joko Lianto Buliali, M.Sc.,Ph.D

Prof. Dr.rer.nat. Achmad Benny Mutiara, SSi, SKom

Prof. Dr. Moedjiono. MSc

Dr. Winarno

Dr. Harco Lesly

Panca Oktavia Hadi Putra, Bsc., M.Sc.,

Henderi, M.Kom

Dr. Ir. I. Joko Dewanto, MM

Dr. Ir. Sudaryono, S.Pd., M.Pd

\section{Editor/ Layout :}

Yuli Widiastuti

\section{Bendahara:}

Eka Purnama Harahap, S.Kom

\section{Alamat Redaksi :}

Jl. Jendral Sudirman No 40, Cikokol - Tangerang Tel / fax : (021)5529692

Email: ijc@ raharjagroups.info atau ijc@ raharja.info 


\section{Dewan Redaksi}

Puji dan syukur kehadirat Allah SWT atas karunia dan lindunganNya sehingga TMJ terbitan Vulume 1 Nomor 2 Edisi Februari 2017 dapat diterbitkan tepat waktu.

Penerbitan jurnal ini dimaksudkan sebagai media informasi ilmiah dibidang ilmu komputer yang diharapkan dapat membantu para dosen dan mahasiswa dalam menginformasikan hasil penelitian dan kajian ilmiah lainnya kepada berbagai komunitas ilmiah diseluruh Indonesia.

Penerbitan jurnal Volume 1 Nomor 2 Edisi Februari 2017 berisikan 10 artikel yang mencakup bidang Ilmu Komputer, Teknologi Informasi, Sistem Informasi, walaupun tidak seluruhnya merupakan hasil penelitian diharapkan dapat bermanfaat bagi pembacanya. Puji syukur kehadirat Allah SWT karena 10 artikel adalah dari STMIK dan AMIK Raharja.

Jurnal ini diterbitkan dengan memuat artikel Notifikasi Pembelajaran iLearning Melalui Media Aplikasi Idu Dengan Menggunakan E-Mail Rinfo, Aplikasi Sistem Penjualan Sparepart Motor Pada Bengkel Barokah Motor Berbasis Web, Penerapan Idu Ilearning Plus Berbasis Gamification Sebagai Media Pembelajaran Jarak Jauh Pada Perguruan Tinggi, Perancangan Aplikasi Pen+ Berbasis Mobile Untuk Memudahkan Kinerja Dosen Pada Perguruan Tinggi, Optimalisasi Single Sign On Untuk Meningkatkan Sistem Keamanan Ojrst, Pemanfaatan Fungsi Etalase Artikel Untuk Meningkatkan Traffic Rank Website Zpreneur, Penerapan Go+ Berbasis Web Untuk Meningkatkan Mutu Pelayanan Lembaga Keuangan Mahasisiwa, Penerapan Inbound Official Site Sistem Informasi Untuk Meningkatkan Rank Webometrics, Perancangan Sistem Absensi Online Menggunakan Android Guna Mempercepat Proses Kehadiran Karyawan Pada Pt. Sintech Berkah Abadi .

Tidak lupa pula pada kesempatan ini kami mengundang para pembaca untuk mengirimkan naskah hasil penelitian kepada kami. Dan tidak lupa pula kami mengucapkan banyak terimakasih kepada semua pihak yang telah membantu penerbitan jurnal ini.

Tangerang, 29 Februari 2017 


\section{Daftar Isi}

1. NOTIFIKASI PEMBELAJARAN ILEARNING MELALUI MEDIA APLIKASI IDU DENGAN MENGGUNAKAN E-MAIL RINFO ....

Qurotul Aini, Rubin Hakita Irwin, Eka Marjayanti

2. PENERAPAN TICKETING OJRS+ BERBASIS ONLINE UNTUK KEBUTUHAN BATAL TAMBAH PERKULIAHAN MAHASISWA

Ary Budi Warsito, Khanna Tiara, Siti Ela Rohilah

3. APLIKASI SISTEM PENJUALAN SPAREPART MOTOR PADA BENGKEL BAROKAH MOTOR BERBASIS WEB.

Aris, Mochamad Rinja, Taufan Jherico

4. PENERAPAN IDU ILEARNING PLUS BERBASIS

GAMIFICATION SEBAGAI MEDIA PEMBELAJARAN JARAK

JAUH PADA PERGURUAN TINGGI............................

Qurotul Aini, Hani Dewi Ariesanti, Kitab Suci

5. PERANCANGAN APLIKASI PEN+ BERBASIS MOBILE UNTUK MEMUDAHKAN KINERJA DOSEN PADA PERGURUAN TINGGI

Untung Rahardja Nikita Jova Tejosuwito, Fernanda Setyobudi Armansyah

6. OPTIMALISASI SINGLE SIGN ON UNTUK MENINGKATKAN SISTEM KEAMANAN OJRS+

Khanna Tiara, Fella Megita Putri, Heni Triyani

7. PEMANFAATAN FUNGSI ETALASE ARTIKEL UNTUK MENINGKATKAN TRAFFIC RANK WEBSITE ZPRENEUR.

Untung Rahardja, Qurotul Aini, Rista Meytasari

8. PENERAPAN GO+ BERBASIS WEB UNTUK MENINGKATKAN MUTU PELAYANAN LEMBAGA KEUANGAN MAHASISIWA..

Khanna Tiara, Tuti Nurhaeni, Yeti Faradisa

9. PENERAPAN INBOUND OFFICIAL SITE SISTEM INFORMASI UNTUK MENINGKATKAN RANK WEBOMETRICS.

Untung Rahardja, Qurotul Aini, Lily Ratna Sulantrini

10. PERANCANGAN SISTEM ABSENSI ONLINE MENGGUNAKAN ANDROID GUNA MEMPERCEPAT PROSES KEHADIRAN KARYAWAN PADA PT. SINTECH BERKAH ABADI............. 


\title{
Penerapan Inbound Official Site Sistem Informasi Untuk Meningkatkan Rank Webometrics
}

\author{
Untung Rahardja ${ }^{1}$ \\ Qurotul Aini ${ }^{2}$ \\ Lily Ratna Sulastrini ${ }^{3}$ \\ Dosen STMIK Raharja ${ }^{1,2}$, Mahasiswa STMIK Raharja ${ }^{3}$ \\ E-mail: untung@raharja.info ${ }^{1}$; aini@raharja.info ${ }^{2}$; lilyratna@raharja.info ${ }^{3}$
}

\begin{abstract}
A college or education institutions surely has an official website adahal mandatory. Due to the existence of official website can help promote a Community College to the wider audience again. Raharja has various College official website, ranging from websites belonging to Raharja College itself and there is also a website belonging to any existing majors in College Raharja, an example is the website belonging to the information system with the url si.raharja.ac.id. In this study the problems encountered was the subject of inbound for website information systems, due to the presence of many inbound surely will make the website better known more information system especially for the Personal information systems majors Raharja as containers to get accurate information. There are 10 (ten) study to support the development of the library information system website. Stage of implementation is done by installing the inbound information systems across various other websites. The end result of this research done by Webometrics uses to monitor the rank on the website raharja.ac.id. Expected number of inbound able to improve rank webometrics website at raharja.ac.id.
\end{abstract}

Keywords: Webometrics, Information System, Inbound

\begin{abstract}
ABSTRAKSI
Sebuah Perguruan Tinggi atau instansi pendidikan tentunya memiliki sebuah official website adalah hal yang wajib. Karena dengan adanya official website dapat membantu mempromosikan suatu perguruan tinggi ke khalayak yang lebih luas lagi. Perguruan Tinggi Raharja memiliki berbagai official website, mulai dari website milik Perguruan Tinggi Raharja sendiri dan ada juga website milik setiap jurusan yang ada di Perguruan Tinggi Raharja, contohnya adalah official site milik jrursan Sistem Informasi dengan url si.raharja.ac.id, namun dalam penelitian ini permasalahan yang dihadapi adalah perihal inbound untuk website Sistem Informasi, karena dengan adanya banyak inbound tentunya akan membuat official site Sistem Informasi lebih dikenal lagi khususnya bagi para Pribadi Raharja jurusan Sistem Informasi sebagai wadah untuk mendapatkan informasi yang akurat. Terdapat 10 (sepuluh) study pustaka untuk menunjang perkembangan website Sistem Informasi ini. Tahap implementasi yang dilakukan adalah dengan memasang inbound Sistem Informasi di berbagai website lain. Hasil akhir penelitian ini dilakukan dengan cara menggunakan Webometrics untuk memantau rank pada
\end{abstract}

105 | Untung, Qurotul, Lily - Penerapan Inbound Official Site ... 
website raharja.ac.id. Diharapkan dengan banyaknya inbound mampu meningkatkan rank webometrics pada website raharja.ac.id.

Kata Kunci: Webometrics, Sistem Informasi, Inbound

\section{PENDAHULUAN}

Di masa yang sudah semakin mutakhir tentunya masyarakat luas sudah akrab dengan berbagai kemajuan pesat yang ada saat ini. Khususnya dengan hal-hal atau berita-berita yang bersifat online, misalnya adalah dengan adanya sebuah website. Bagi masyarakat kalangan tertentu khususnya suatu kampus tentunya sebuah official site menjadi suatu hal yang penting karena kita bisa mendapatkan berita tertentu dari sebuah official site. Macamnya pun beragam, ada website pribadi yang dimiliki oleh seseorang dan aja juga official website misalnya milik perusahaan atau milik suatu kampus atau instansi tertentu.

Sebuah Perguruan Tinggi unggulan tentunya memiliki sebuah official site adalah hal yang penting, karena sebagai sarana promosi kepada masyarakat luas dan juga sebagai sarana pendukung suatu Perguruan Tinggi. Official site nya pun harus berisikan dengan informasi yang akurat dan up to date seputar kegiatan-kegiatan yang ada pada kampus tersebut agar penyampaian beritanya bisa maksimal. Karena dengan adanya berita yang up to date tentunya bisa menarik minat para pembaca untuk mengunjungi suatu website tersebut.

Dikutip dari halaman webometrics bahwa di tahun 2015 Universitas Indonesia menduduki peringkat pertama sebagai kampus dengan website terbaik di Indonesia dan Universitas Indonesia juga menduduki peringkat 763 sebagai kampus dengan website terbaik di dunia. Tentunya itu adalah pencapaian yang sangat luar biasa bagi sebuah Universitas. Jumlah indikator pemeringkatan yang diterapkan oleh sistem Webometrics berisikan dengan 4 (empat) point yaitu impact (20\%), Presence (50\%), openness (15\%), dan excellence (15\%).

Dengan adanya sistem perangkingan webometrics tersebut tentunya membuat para Universitas atau Perguruan Tinggi berlomba lomba untuk bisa menampilkan sebuah website yang bagus, bahkan bagus saja tidak cukup untuk menghasilkan suatu website yang maksimal, harus dilandasi juga dengan 4 (empat) point diatas yang sudah di tentukan oleh webometrics untuk bisa mendapatkan nilai atau rank yang tertinggi pada perangkingan webometrics.

\section{PERMASALAHAN}

Perguruan Tinggi Raharja yang akrab dengan sebutan Green Campus adalah kampus yang bergerak di bidang ilmu komputer yang sudah terakreditasi dengan baik di Kota Tangerang. Sebagai kampus yang berlatar belakang ilmu komputer tentunya Perguruan Tinggi Raharja harus menyiapkan segala sesuatu yang bersifat online atau terkomputerisasi seiring dengan berjalannya kemajuan teknologi saat ini. Mulai dari pelayanan, pembayaran biaya kuliah, dan juga tentunya official website Perguruan Tinggi Raharja. Karena official site memiliki peran yang sangat penting demi menunjang segala kebutuhan seputar Perguruan Tinggi Raharja. Misalnya seperti sejarah Perguruan Tinggi Raharja, visi dan misi yang diterapkan di Perguruan Tinggi Raharja, 
jurusan atau program study yang ada di Perguruan Tinggi Raharja dan masih banyak hal lain yang bisa kita dapatkan dari official website Perguruan Tinggi Raharja.

Perguruan Tinggi Raharja juga didukung dengan official website yang dimiliki oleh setiap jurusan untuk memaksimalkan pelayanan dan penyampaian informasi kepada para mahasiswa yang biasa disebut dengan Pribadi Raharja. Contohnya adalah website milik jurusan Sistem Informasi dengan url si.raharja.ac.id yang dikelola oleh kepala jurusan Sistem Informasi dan salah satu mahasiswa jurusan Sistem Informasi. Keberadaan website Sistem Informasi tersebut tentunya diharapkan bisa sangat membantu mahasiswa/i untuk mendapatkan informasi seputar event-event yang ada di Perguruan Tinggi Raharja khususnya bagi mahasiswa/i jurusan Sistem Informasi itu sendiri serta bisa membantu meningkatkan rank Perguruan Tinggi Raharja di perangkingan Webometrics. Karena faktanya jika dilihat dari perangkingan webometrics saat ini Perguruan Tinggi Raharja menduduki peringakat ke 303 di Indonesia. Maka dibutuhkan usaha keras dan kekompakan dari seluruh civitas kampus untuk bisa membawa nama Perguruan Tinggi Raharja lebih naik lagi dalam perangkingan Webometrics.

Sebelum adanya official site jurusan Sistem Informasi ini mahasiswa jurusan Sistem Informasi masih cukup kesulitan untuk mendapatkan informasi yang jelas seputar jurusan Sistem Informasi, karena pada official site Perguruan Tinggi Raharja yaitu di url raharja.ac.id hanya menampilkan informasi-informasi yang bersifat umum yang ditujukian bagi semua mahasiswa sehingga tidak bisa menampilkan berita atau informasi yang spesifik bagi mahasiswa jurusan Sistem Informasi. Maka di buatlah official site jurusan Sistem Informasi untuk menunjang kebutuhan mahasiswa jurusan Sistem Informasi untuk mendapatkan informasi yang akurat dan disamping itu juga untuk meningkatkan rank Perguruan Tinggi Raharja di Webometrics.

Namun tidaklah mudah untuk mencapai peringkat yang baik pada webometrics, dibutuhkan berbagai cara untuk bisa mewujudkannya sesuai dengan point-point perhitungan yang sudah diterapkan pada sistem Webometrics. Salah satu cara yang paling ampuh adalah dengan menerapkan inbound untuk website Sistem Informasi di website-website lain. Karena inbound memiliki banyak keuntungan bagi website Sistem Informasi tersebut. Diantaranya adalah untuk mempromosikan keberadaan website Sistem Informasi ke lebih banyak orang diluar sana.

Sebelum adanya Official Site Sistem Informai banyak mahasiswa yang kebingungan untuk mendapatkan informasi seputar jurusan Sistem Informasi misalnya Visi Misi jurusan Sistem Informasi atau seminar-seminar untuk jurusan Sistem Informasi. Para mahasiswa/i harus mengunjungi official website milik Perguruan Tinggi. Aktifitas tersebut menurut penulis kurang efektif karena di official website Perguruan Tinggi Raharja hanya menampilkan informasi yang umum. Namun seiring berjalannya waktu oleh karena itu berdasarkan analisa dari segi kekurangan serta kebutuhan terhadap sistem hendaknya bisa dituangkan pada 3 (tiga) poin berikut:

1. Bagaimana menerapkan Official site Sistem Informasi pada Perguruan Tinggi Raharja?

2. Apakah Strategi yang dapat diterapkan untuk meningkatkan rank Webometrics pada Official website Sistem Informasi?

3. Bagaimana inbound dapat bermanfaat untuk meningkatkan rank Webometrics pada Official site Sistem Informasi? 


\section{METODE PENELITIAN}

Banyak penelitian yang sebelumnya dilakukan mengenai Rank Webometrics pada suatu website dan penelitian lain yang berkaitan. Dalam upaya mengembangkan dan meningkatkan Ranking Webometrics website Sistem Informasi ini perlu dilakukan studi pustaka (literature review) sebagai salah satu dari penerapan metode penelitian yang akan dilakukan. Diantaranya adalah mengidentifikasikan kesenjangan (identify gaps), menghindari pembuatan ulang (reinventing the wheel), mengidentifikasikan metode yang pernah dilakukan, meneruskan penelitian sebelumnya, serta mengetahui orang lain yang spesialisasi dan area penelitiannya sama dibidang ini. 7 (tujuh) Literature review tersebut adalah sebagai berikut :

1. Penelitian yang dilakukan oleh Heru, maulana pada tahun 2012 dalam skripsinya dengan judul "Analisis Perbandingan Rangking Webometrics Universitas Terbaik Di Indonesia Dengan Perangkingan Metode Topsis Dan Vikor". Penelitian ini menggunakan dua instrumen yaitu search engine google dan web crawler socscibot. Jenis penelitian ini adalah penelitian kuantitatif dengan obyek penelitian 30 website akademik perguruan tinggi terbaik di Indonesia sesuai dengan peringkat Webometrics.

2. Penelitian yang dilakukan oleh Mastuti, Wijaya pada tahun 2012 dalam skripsinya dengan judul "Analisis Perbandingan Peringkat 30 Universitas Terbaik Dunia Menurut Rilis Webometrics Dan Hasil Peringkat Dengan Metode Oreste dan Bayesian" Penelitian ini dilakukan untuk mengetahui perbandingan peringkat 30 website universitas terbaik dunia rilis Webometrics dengan hasil peringkat yang dihitung dengan menggunakan 2 metode pemeringkatan yang berbeda.

3. Penelitian yang dilakukan oleh Anandita, Bagus Wicaksono pada tahun 2015 pada skripsinya dengan judul "Analisis Perbandingan Webometrics Rangking Universitas Negeri Dan Swasta Di Indonesia Dengan Perangkingan Metode Promethee Dan Vikor" Penelitian ini dilakukan untuk mengetahui perbandingan peringkat antara perangkingan website akademik di Indonesia dengan menggunakan metode promethee dan vikor dengan hasil perangkingan webometrics. Penelitian ini menggunakan 2 instrumen yaitu search engine google dan web crawler socscibot.

4. Penelitian yang dilakukan oleh Heru Cahya Rustamaji, Herry Sofyan, Rusdita Bazzarudin Suryandaru pada tahun 2012 dengan judul "Aplikasi Berbasis Web Monitoring Peringkat Perguruan Tinggi Di Indonesia Berdasarkan Parameter Webometrics Dan 4ICU" sistem ini dibangun menggunakan bahasa pemograman PHP 5.3.3 dan javascript, RedBean sebagai Framework.

5. Penelitian yang dilakukan oleh Mukhamad Masrur pada tahun 2011. Penelitian ini berjudul 'LANGKAH-LANGKAH STRATEGIS DALAM PENINGKATAN DAYA SAING UNIVERSITAS MENGGUNAKAN TEKNOLOGI INFORMASI". Beberapa strategi agar web universitas dapat meningkat peringkatnya dalam webometric adalah dengan meningkatkan hal-hal menjadi penilaian dari webometric. Hal ini berarti perlu dilakukan langkah-langkah dalam meningkatkan seperti size,visibility, richfile, scholar. Dalam meningkatkan daya saing menggunakan langkah strategi melalui Search Engine 
Optimization (SEO) dan webometric sebagai jalur alternative pencapaian cita-cita menuju World Class University yang semakin terbuka.

6. Penelitian ini dilakukan oleh Achmad Solichin pada tahun 2011. Yang berjudul "STRATEGI PENINGKATAN PERINGKAT PERGURUAN TINGGI DI WEBOMETRICS : STUDY KASUS UNIVERSITAS BUDI LUHUR ”. Peringkat Webometrics merupakan perangkat universitas dunia yang dikeluarkan oleh Cybermatrics Lab, sebuah group penelitian yang merupakan bagian dari National Research Council (CSIC),spanyol. Cybermatrics Lab mempublikasikan peringkat perguruan tinggi seluruh dunia setiap enam bulan sekali, yaitu bulan januari dan juli. Peringkat webometrics saat ini menjadi salah satu indikator kualitas perguruan tinggi di dunia.

7. Penelitian ini dilakukan oleh Supradono, Bambang pada tahun 2010 dalam jurnalnya yang berjudul "STRATEGI MENINGKATKAN KINERJA WEB UNIVERSITAS MUHAMMADIYAH SEMARANG MENUJU PERINGKAT WEBOMETRICS” Vol 3. No 1 (2010) Penelitian ini dilakukan sebagai strategi UNIMUS menuju peringkat webometrics.

Dari 7 (tujuh) literature review yang ada, telah banyak penelitian mengenai Peningkatan Web Rank. Namun dapat disimpulkan pula bahwa belum ada peneliti yang secara khusus membahas mengenai Penerapan Teknik inbound pada suatu official site Untuk Meningkatkan Rank Webometrics.

\section{HASIL DAN PEMBAHASAN}

Perguruan Tinggi Raharja sebagai sebuah kampus yang bergerak di ilmu komputer, tentunya sudah sangat akrab dengan segala sesuatu yang bersifat online. Misalnya adalah dengan hadirnya sebuah official site jurusan Sistem Informasi. Setelah mengamati serta meninjau dari sudut permasalahan yang telah terjadi di dalam sistem yang sudah berjalan dan penulis memiliki 3 (tiga) pilihan alternatif pemecahan masalah untuk memperkenalkan official site jurusan Sistem Informasi, yaitu sebagai berikut:

a. Memasang inbound official site jurusan Sistem Informasi di akun social media

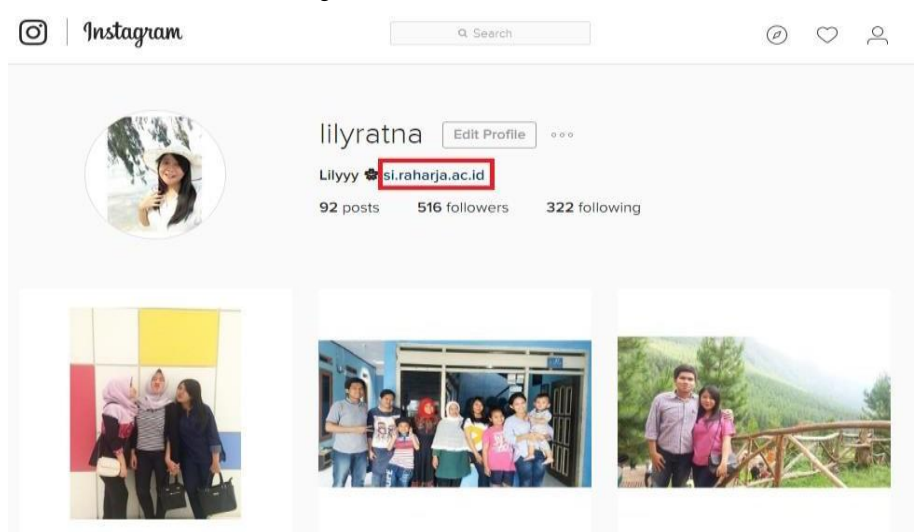

Gambar 1. Inbound pada social media instagram 
b. Melakukan postingan pada social media Facebook tentang keberadaan official site jurusan Sistem Informasi

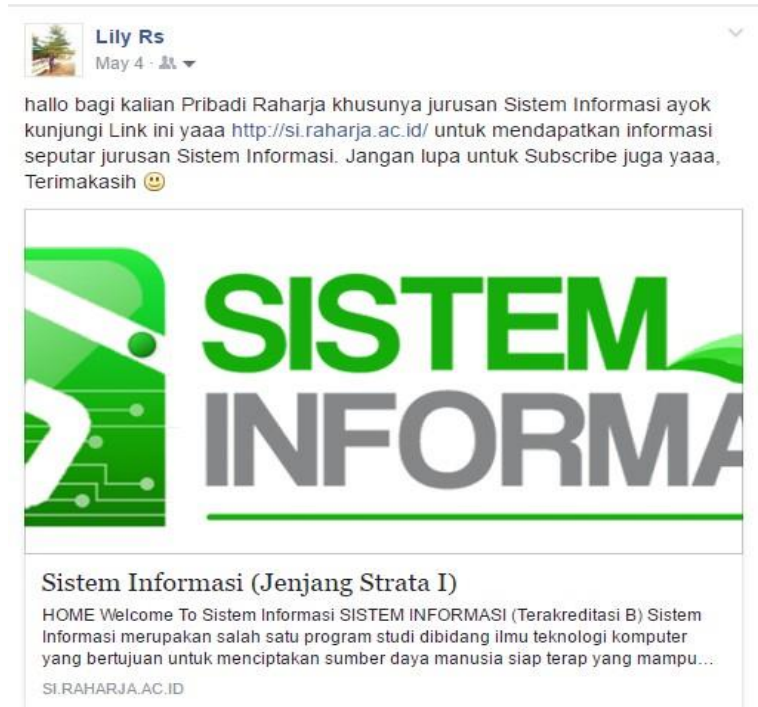

Gambar 2. Inbound pada postingan di Facebook

c. Melakukan postingan pada social media Line tentang keberadaan official site jurusan Sistem Informasi

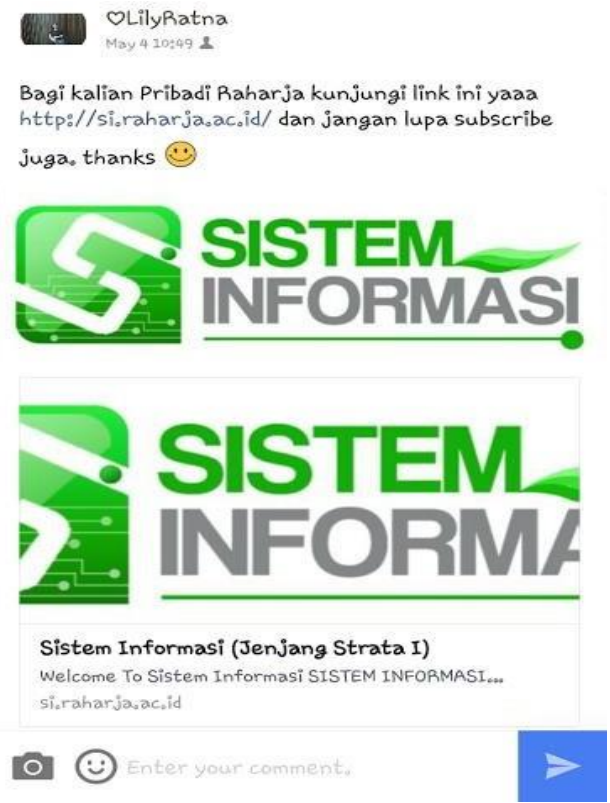

Gambar 3. Inbound pada postingan di Line 


\section{Keistimewaan Website Sistem Informasi}

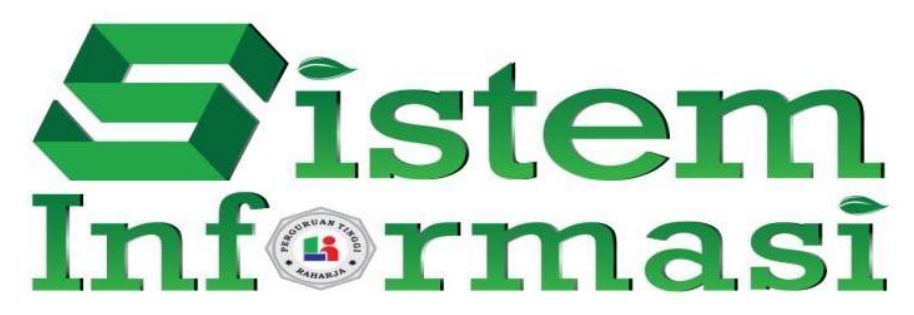

Gambar 4. Logo Sistem Informasi

Official Site Sistem Informasi adalah sebuah Official Site istimewa yang berada di Perguruan Tinggi Raharja yang tergabung dalam Man Of 20 yaitu kumpulan 20 Official Site yang diciptakan oleh Perguruan Tinggi Raharja yang bertujuan untuk membantu meningkatkan rank Perguruan Tinggi Raharja di Webometrics. Karena konten-konten yang terdapat di official site jurusan Sistem Informasi sudah menyajikan informasi yang akurat seputar jurusan Sistem Informasi serta memiliki banyak inbound di website-website yang berada di luar Perguruan Tinggi Raharja, maka dari itu website sistem Informasi mampu meraih nilai $100 \%$ dari peniliain team Webometrics Perguruan Tinggi Raharja karena telah memenuhi kriteria-kriteria yang di tetapkan oleh team Webometrics Perguruan Tinggi Raharja.

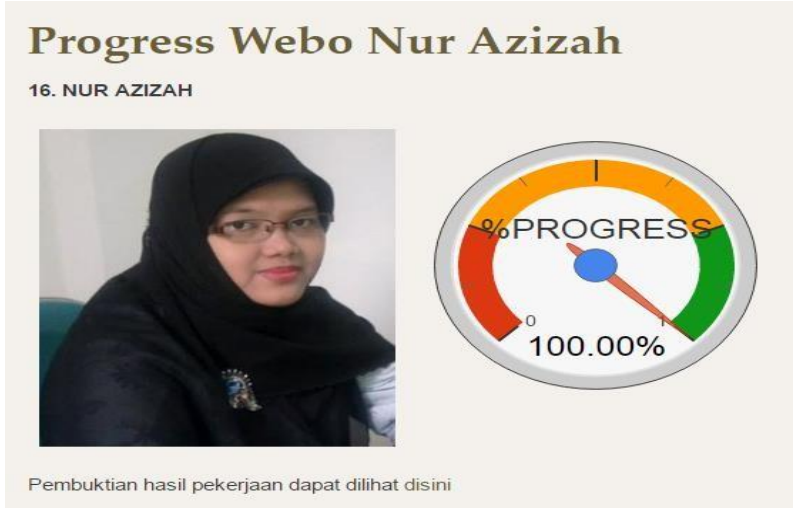

Gambar 5. Hasil Penilaian team webometrics Perguruan Tinggi Raharja

\section{Tujuan Official Site Sistem Informasi}

Terciptanya official site Sistem Informasi ini bertujuan untuk dijadikan wadah bagi mahasiswa/i jurusan Sistem Informasi untuk mendapatkan informasi yang akurat seputar jurusan Sistem Informasi dan yang terakhir adalah untuk membantu meningkatkan rank Peguruan Tinggi Raharja di webometrics. 


\section{Implementasi}

Tampilan website setelah Login menggunakan Rinfo dan kita dapat mengakses semua fitur menu yang terdapat pada Official site Sistem Informasi. Berikut ini adalah Tampilan Official site Sistem Informasi yang memiliki berbagai macam fitur di dalamnya yang dapat digunakan oleh siapa saja, baik itu dosen, mahasiswa/i maupun masyarakat lainnya dan terdapat 8 (delapan) menu yang dapat diakses pada tampilan home user yaitu:

\subsection{Login}

Langkah awal agar admin bisa membuat postingan kedalam Official Site jurusan.

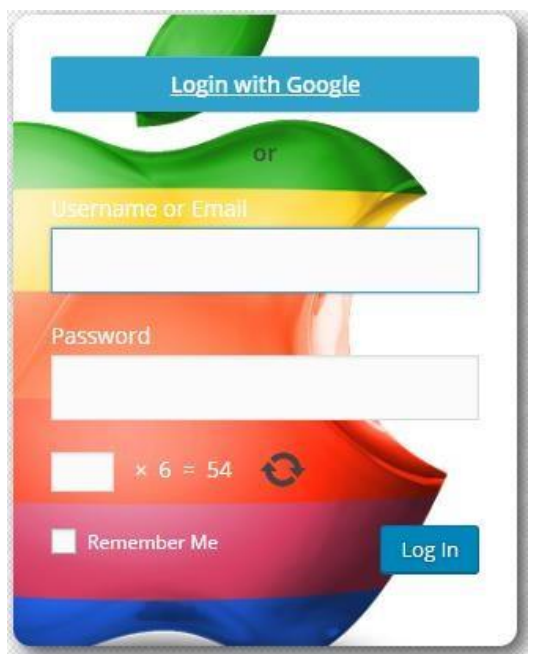

Gambar 6. Tampilan Login untuk admin menggunakan SSO iMe.

\subsection{Home}

Tampilan utama yang berisi logo Sistem Informasi dan berbagai menu yang terdapat di dalamnya. 


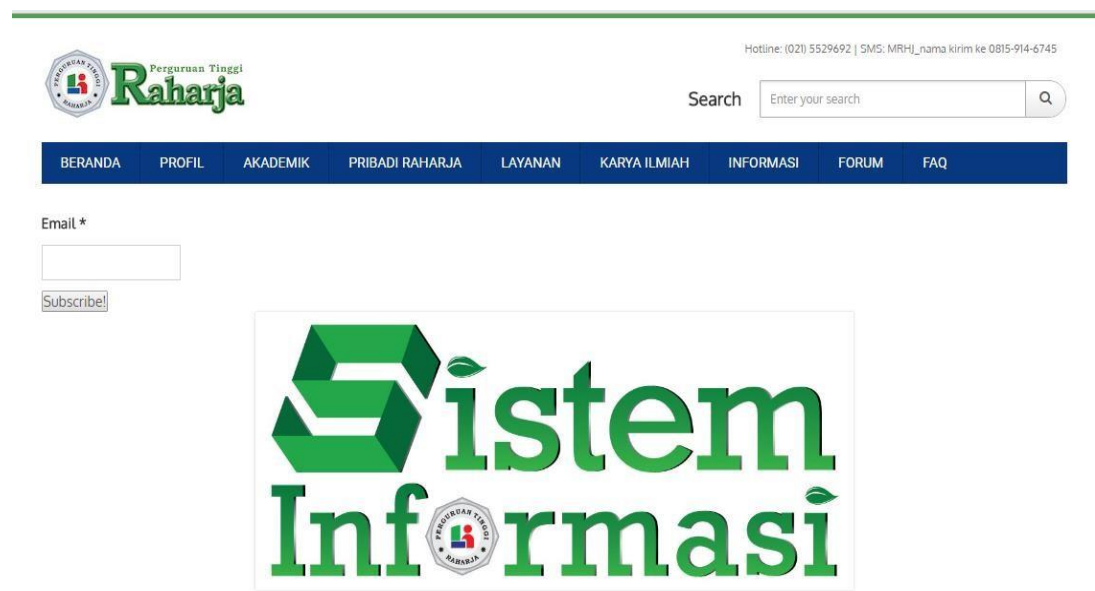

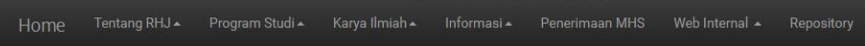

Gambar 7. Tampilan Home Official Site Jurusan Sistem Informasi

\subsection{Komunitas Mahasis wa Sistem Informasi}

Berisi komunitas yang dimiliki oleh mahasiswa/i jurusan Sistem Informasi.

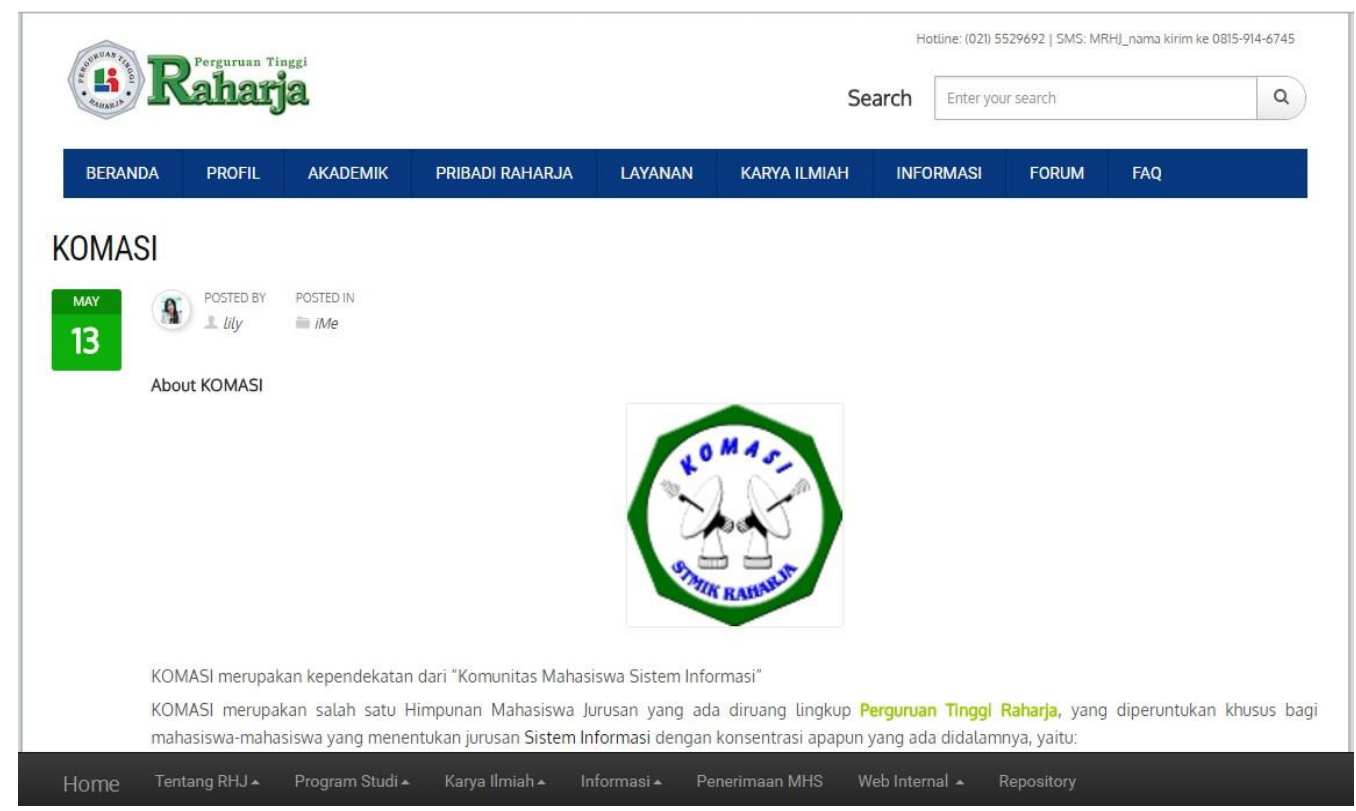

Gambar 8. Tampilan komunitas komasi

\subsection{Daftar Nama Dosen Pengajar di Jurusan Sistem Informasi Berisi profil dosen pengajar di Jurusan Sistem Informasi}




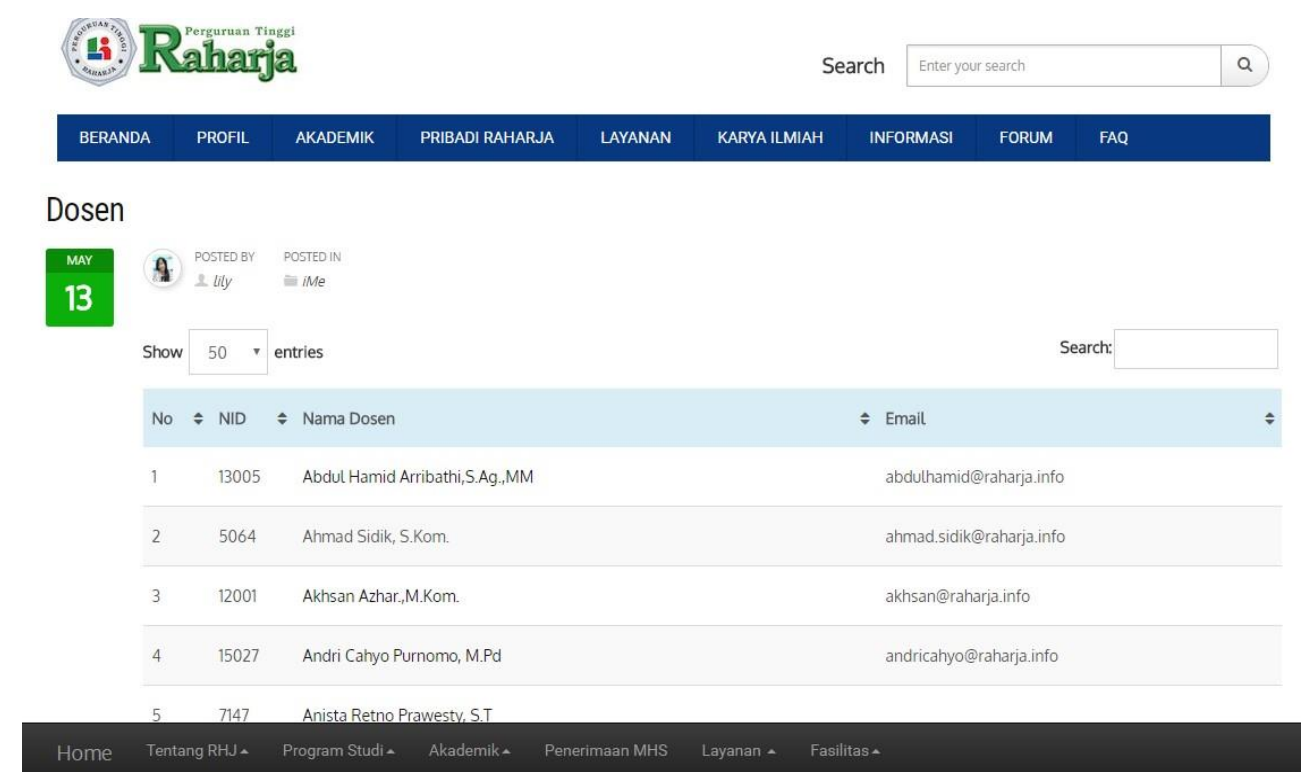

Gambar 9. Daftar nama dosen pengajar di Jurusan Sistem Informasi

\section{KESIMPULAN}

Menerapkan official site Jurusan Sistem Informasi sebagai wadah bagi mahasiswa/i jurusan Sistem Informasi untuk mendapatkan informasi yang akurat seputar jurusan Informasi serta untuk menaikkan rank Perguruan Tinggi Raharja di Webometrics. Strategi yang dapat diterapkan untuk menaikkan rank website Perguruan Tinggi Raharja di webometrics dilakukan dengan beberapa strategi, salah satu strategi yang bisa diterapkan menurut penulis adalah dengan cara memperkaya inbound untuk website Sistem Informasi yang gunanya untuk memperkenalkan keberadaan website Sistem Informasi ke khalayak yang lebih luas. Dengan banyaknya inbound untuk website Sistem Informasi ini juga diharapkan mampu membantu meningkatkan rank Perguruan Tinggi Raharja di Webometrics

\section{SARAN}

Untuk memajukan official site tersebut didapatkan beberapa saran yang diharapkan bisa dijadikan referensi guna memajukan official site tersebut, diantaranya:

1. Diharapkan sistem ini dapat dikembangkan kembali oleh penerus yang lainnya demi menyempurnakan official site jurusan Sistem Informasi tersebut.

2. Diharapkan dengan hadirnya official site jurusan Sistem Informasi ini dapat menjawab kebutuhan dosen serta mahasiswa jurusan Sistem Informasi demi mendapatkan informasi yang up to date seputar jurusan tersebut.

3. Diharapkan dengan adanya strategy untuk inbound dan outbound ke berbagai pihak luar dapat membantu meningkatkan rank Perguruan Tingi Raharja pada Webometrics. 


\section{DAFTAR PUSTAKA}

[1] Webometrics. Rank Perguruan Tinggi Raharja. Diakses pada tanggal 1 Juni 2016. Tersedia di http://www. webometrics.info/en/Asia/Indonesia\%20?page=3

[2] Heru, maulana. 2012. "Analisis Perbandingan Rangking Webometrics Universitas Terbaik Di Indonesia Dengan Perangkingan Metode Topsis Dan Vikor"

[3] Mastuti, Wijaya. 2012. "Analisis Perbandingan Peringkat 30 Universitas Terbaik Dunia Menurut Rilis Webometrics Dan Hasil Peringkat Dengan Metode Oreste dan Bayesian"

[4] Anandita, Bagus Wicaksono. 2015. "Analisis Perbandingan Webometrics Rangking Universitas Negeri Dan Swasta Di Indonesia Dengan Perangkingan Metode Promethee Dan Vikor"

[5] Heru Cahya Rustamaji, Herry Sofyan, Rusdita Bazzarudin Suryandaru. 2012. "Aplikasi Berbasis Web Monitoring Peringkat Perguruan Tinggi Di Indonesia Berdasarkan Parameter Webometrics Dan 4ICU"

[6] Mukhamad, Masrur.2011.'LANGKAH-LANGKAH STRATEGIS DALAM PENINGKATAN DAYA SAING UNIVERSITAS MENGGUNAKAN TEKNOLOGI INFORMASI".

[7] Achmad Solichin. 2011. "STRATEGI PENINGKATAN PERINGKAT PERGURUAN TINGGI DI WEBOMETRICS : STUDY KASUS UNIVERSITAS BUDI LUHUR ”.

[8] Supradono, Bambang. 2010. "STRATEGI MENINGKATKAN KINERJA WEB UNIVERSITAS MUHAMMADIYAH SEMARANG MENUJU PERINGKAT WEBOMETRICS" Vol 3. No 1 (2010) 